\title{
Establishment of an immortalized human extravillous trophoblast cell line by retroviral infection of E6/E7/hTERT and its transcriptional profile during hypoxia and reoxygenation
}

\author{
HIROKO OMI ${ }^{1}$, AIKOU OKAMOTO ${ }^{1,2}$, TAKASHI NIKAIDO ${ }^{3}$, MITSUYOSHI URASHIMA ${ }^{4}$, \\ RIE KAWAGUCHI ${ }^{1}$, NAGAYOSHI UMEHARA ${ }^{1}$, KENTARO SUGIURA ${ }^{1}$, \\ MISATO SAITO $^{1}$, TOHRU KIYONO ${ }^{5}$ and TADAO TANAKA ${ }^{1}$ \\ Departments of ${ }^{1}$ Obstetrics and Gynecology, ${ }^{2}$ Gene Therapy, Institute of DNA Medicine, \\ ${ }^{3}$ Department of Pathology, ${ }^{4}$ Division of Clinical Research and Development, The Jikei University, \\ School of Medicine, 3-25-8 Nishishinbashi, Minato-ku, Tokyo 105-8461; ${ }^{5}$ Virology Division, \\ National Cancer Center Research Institute, 5-1-1 Tsukiji, Chuo-ku, Tokyo 104-045, Japan
}

Received September 26, 2008; Accepted October 29, 2008

DOI: 10.3892/ijmm_00000121

\begin{abstract}
Investigation into the function of human trophoblasts has been largely restricted by a lack of suitable cell models. We aimed to produce normal human trophoblast cell lines with a long lifespan and to provide an ideal in vitro cell model. Primary human trophoblast cells were derived from a placenta that had undergone elective abortion at the 7 th week of gestation. The cells were immortalized by infection with retroviral expression vectors containing the type 16 human papillomaviruses E6 and E7 in combination with human telomerase reverse transcriptase (hTERT). Characterization of the cell line was performed by immunocytochemistry using a panel of antibodies, Western blotting, real-time RT-PCR, an invasion assay, gelatin zymography, karyotype analysis and a nude mouse assay. Gene expression profiles under hypoxia $\left(1 \% \mathrm{O}_{2}, 1 \mathrm{~h}\right)$ and subsequent reoxygenation $\left(20 \% \mathrm{O}_{2}, 6 \mathrm{~h}\right)$ were analyzed using cDNA microarray. Immunocytochemistry revealed an extravillous trophoblastic phenotype by positive staining for hCGß, cytokeratin 7, HLA-G and CD9. A transwell insert invasion assay showed the invasiveness of this cell line and gelatin zymography detected the secretion of MMP-2 and MMP-9. Karyotype analysis exhibited an almost normal chromosomal number which ranged from 46 to 48 and the cells showed no tumorigenecity in a nude mouse assay. Forty-three genes showing reversible up- or down-regulation during hypoxia were detected using an oligonucleotide array.
\end{abstract}

Correspondence to: Dr Tadao Tanaka, Department of Obstetrics and Gynecology, The Jikei University, School of Medicine, 3-25-8 Nishishinbashi, Minato-ku, Tokyo 105-8461, Japan

E-mail: tanaka3520@jikei.ac.jp

Key words: trophoblast, immortalization, human papillomavirus, E6, $\mathrm{E} 7$, human telomerase reverse transcriptase, hypoxia, oligonucleotide microarray
This newly immortalized cell line, HChEpC1b, is a useful model for the study of extravillous trophoblast function.

\section{Introduction}

In humans, cells outside the morula form the trophoectoderm and differentiate into trophoblasts. These cells form the fetal compartment of the placenta during pregnancy. After the initial phase of implantation, human trophoblasts differentiate along either the villous or the extravillous trophoblast pathway. Multinucleate syncytiotrophoblasts, which form the epithelial layer of the villi by cell fusion, are involved in the exchange of gas and the nutrients between the mother and the fetus. Mononuclear extravillous cytotrophoblasts invade deep into the decidua, the myometrium and the uterine spiral arteries (1). Clinically, many pregnancy-associated conditions result from abnormal functioning of trophoblasts, such as abortion, intrauterine growth retardation and pre-eclampsia (2).

Investigation into the function of human trophoblasts has been largely restricted by the short life span of primary cultured trophoblasts in vitro. There are two major mechanisms that cause the limited life span of primary cultured cells. One is the telomere-based replication senescence $(3,4)$ and the other is telomere-independent senescence, which is thought to be controlled by the Rb/p16 (5) and p53 pathways (6). Since HPV16 E6/and E7 are known to inhibit p53 and Rb function, respectively, we introduced E6/E7 and human telomerase reverse transcriptase (hTERT) into primary human trophoblast cells to immortalize them.

We obtained one cell line, HChEpC1b, that retained an extravillous phenotype and acquired immortality. This cell line expressed molecular markers for human extravillous trophoblasts and it demonstrated invasiveness and metalloproteinase production; nevertheless, it did not show tumorigenic potency. There have been a number of trophoblast cell lines that have gained a long life span spontaneously (7-12), or by transduction of the SV40 T antigen (7,13-17), HPV16 E6/E7 $(18,19)$ and hTERT $(20)$. However, this is the 
first study of an immortalized trophoblast cell line produced by retroviral infection of HPV16 E6/E7 in combination with hTERT and this newly established cell line may provide a useful model for the study of extravillous trophoblast function as well as that of other cell lines.

\section{Materials and methods}

Preparation of human trophoblast primary cultures. A human placenta was obtained from a patient that had undergone a legal termination of a normal pregnancy at 7 weeks of gestation with informed consent. This study was approved by the Ethics Committee of the Jikei University. After removal of all attached decidual tissue and blood clots, chorionic villi were gently shaken in normal saline solution. The fallen cells and tissue fragments were collected and suspended in RPMI-1640 (Sigma-Aldrich, Tokyo, Japan) supplemented with $10 \%$ fetal bovine serum (Invitrogen Corp., Carlsbad, CA, USA), $50 \mathrm{IU} / \mathrm{ml}$ penicillin, $50 \mu \mathrm{g} / \mathrm{ml}$ streptomycin, and $100 \mathrm{mg} / \mathrm{ml}$ neomycin (Invitrogen Corp) and were cultured in a collagen I coated culture dish (Asahi Techno Glass, Tokyo, Japan). Two weeks later, colonies were collected using cloning rings with $0.05 \%$ trypsin and $0.53 \mathrm{mM}$ EDTA (Invitrogen Corp) and were transferred to a 24-well culture dish. When the colonies became confluent, the cells were transferred to a 6-well culture dish. Three clones with epithelioid phenotypes [human chorionic epithelium cell-1 (HChEpC1) a-c] were selected for the next immortalization step.

Vector construction and retroviral transduction of E6/E7 and hTERT. Construction of retroviral vector plamids, pCMSCV puro-hTERT, pCLXSN-16E6E7, has been described previously (21). Production of recombinant retroviruses was carried out, as previously described (22). Briefly, a retroviral vector and packaging construct, pCL-10A1, was co-transduced into 293T cells using TransIT-293 (Mirus Bio Corp., Madison, WI, USA) according to the manufacturer's instructions. The culture fluid was harvested at 48 to $72 \mathrm{~h}$ post-transduction. The titer of the recombinant viruses was $>1 \times 10^{5}$ drugresistant colony-forming $\mathrm{U} / \mathrm{ml}$ on HeLa cells. HChEpC1 cells seeded on 24-well dishes were inoculated with a $0.5 \mathrm{ml}$ aliquot of the culture fluid in the presence of polybrene (4 $\mu \mathrm{g} / \mathrm{ml})$. Following inoculation with viruses, the cells were grown without drug selection as mock-infected cells and stopped growing within two weeks. To achieve different combinations of retroviral infections, the cells were serially infected with MSCVpuro-hTERT and LXSN-16E6E7 at passage 2 .

Cell culture. The infected HChEpC1 cells were cultured in RPMI-1640 supplemented with $10 \% \mathrm{FBS}, 50 \mathrm{U} / \mathrm{ml}$ penicillin $\mathrm{G}, 50 \mu \mathrm{g} / \mathrm{ml}$ streptomycin, and $100 \mathrm{mg} / \mathrm{ml}$ neomycin and were incubated in $5 \% \mathrm{CO}_{2}$ air at $37^{\circ} \mathrm{C}$. Serial passages were made in one to four splits. One clone, $\mathrm{HChEpC1b}$, was selected for further characterization because it had the highest purity of trophoblast cells as proved by its uniformly positive staining for hCGß. The population doubling time (DT) was calculated as follows: DT $=\mathrm{T} \times \log _{2} / \log \left(\mathrm{N}_{\mathrm{T}} / \mathrm{N}_{0}\right)$, where $\mathrm{N}_{0}$ is the initial number of cells and $\mathrm{N}_{\mathrm{T}}$ is the number of cells harvested after $\mathrm{T}$ h culture.
The choriocarcinoma cell lines JAR and JEG-3 and the fibroblast cell line Hs795Pl were obtained from ATCC and propagated in RPMI-1640, MEM (Invitrogen Corp) and DMEM (Invitrogen Corp) respectively, supplemented with $10 \%$ FBS.

Karyotyping. Cells in the exponential phase were arrested by adding $0.03 \mu \mathrm{g} / \mathrm{ml}$ of colchicine for $6 \mathrm{~h}$, before being treated with hypotonic solution ( $75 \mathrm{mM} \mathrm{KCl}, \mathrm{pH} 8.0)$ and fixed twice in Carnoy's fixative (methanol/acetic acid). The G-band pattern was obtained using Giemsa staining and the chromosomes of 20 metaphases were analyzed.

Nude mouse assay. Single cell suspensions ( $10^{7}$ cells) of HChEpC1b cells or JAR cells were subcutaneously inoculated into the right flank of 5 female mice (balb/c nu/nu) each. These mice were observed for up to 3 months and examined for tumor growth.

Immunocytochemistry. $\mathrm{HChEpC1b}$ cells were cultured on collagen I coated culture slides (BD Biosciences, Bedford, MA, USA) for two days, washed once with phosphatebuffered saline (PBS, pH 7.4) and fixed with $100 \%$ ethanol (room temperature) for $30 \mathrm{~min}$. After three 5-min hydration periods in distilled water (room temperature) and two 10-min periods of washing in $0.1 \%$ Tween in $\operatorname{PBS}\left(4^{\circ} \mathrm{C}\right)$, the cells were incubated overnight at $4^{\circ} \mathrm{C}$ with the primary antibodies diluted in Antibody Diluent (Dako, Glostrup, Denmark) as described in Table I. The cells were washed three times with $0.1 \%$ Tween in PBS $\left(4^{\circ} \mathrm{C}\right)$ and incubated with EnVision Labelled Polymer, Peroxidase (Dako) for $1 \mathrm{~h}$ at room temperature. After washing three times with $0.1 \%$ Tween in PBS $\left(4^{\circ} \mathrm{C}\right)$, visualization was developed according to the manufacturer's instructions using diaminobenzidine (DAB) as the substrate. The cells were counterstained with hematoxylin, dehydrated and mounted for light microscopy.

Real-time reverse transcriptase polymerase chain reaction (real-time $R T$-PCR). Total RNA were isolated from subconfluent cultured cells using the RNeasy mini kit (Qiagen, Gmbh Hilden, Germany). Reverse transcription was performed according to the manufacturer's protocol (Takara RNA PCR kit, Takara, Shiga, Japan) with $1 \mu \mathrm{g}$ of total RNA. For realtime PCR, each target was amplified on the same plate with GAPDH as the reference using the Taq Man Universal PCR master mix and the ABI PRISM 7700 sequence detection system (Applied Biosystems, Foster City, USA) and the relative mRNA amounts and range were determined. The primer/probe sets were purchased from Taq Man gene expression assays (Applied Biosystems, Assay IDs are listed in Table II). Relative mRNA levels were calculated by the comparative $\mathrm{C}_{\mathrm{T}}$ method described in $\mathrm{ABI}$ User Bulletin 2 .

Western blotting. Subconfluent HChEpC1b, JAR, JEG-3 and Hs795Pl cells were scraped from culture dishes, washed three times with cold PBS, and then incubated in the RIPA buffer [10 mM Tris- $\mathrm{HCl}$ (pH 7.5), $150 \mathrm{mM} \mathrm{NaCl}, 2$ mM EDTA, $1 \%$ NP-40, $1 \%$ sodium deoxycholate, $0.1 \%$ SDS, complete mini (Roche, Basel, Switzerland)] for $30 \mathrm{~min}$ on ice. After centrifugation, the supernatants were subjected to Western blot 
Table I. Antibodies used for immunocytochemistry and Western blotting.

\begin{tabular}{|c|c|c|c|c|c|c|c|}
\hline Epitope & Clone name & Host & Isotype & Company & Cat. no. & Nation & Dilution \\
\hline Cytokeratin 7 & OVTL 12-30 & Mouse & $\operatorname{IgG} 1 \kappa$ & Acris Antibodies & DM057 & Germany & $1: 50$ \\
\hline HLA class I & W6/32HL & Mouse & $\operatorname{IgG} 2 \mathrm{a}$ & Chemicon International & CBL139 & USA & $1: 50$ \\
\hline HLA-G & $87 \mathrm{G}$ & Mouse & $\operatorname{IgG} 2 \mathrm{a}$ & Exbio & $10-437-\mathrm{C} 100$ & Czech & $1: 100$ \\
\hline HLA-G & MEM-G/1 & Mouse & $\operatorname{IgG} 1$ & Serotec & MCA2043 & UK & $1: 50$ \\
\hline CD9 & Polyclonal & Rabbit & $\operatorname{IgG}$ & Santa Cruz Biotechnology & sc-9148 & USA & $1: 50$ \\
\hline CD9 & M-L13 & Mouse & $\operatorname{IgG1} \kappa$ & BD Biosciences & 555370 & USA & $1: 50$ \\
\hline Vimentin & V9 & Mouse & IgG1 & Chemicon International & MAB3400 & USA & $1: 200$ \\
\hline E-cadherin & Polyclonal & Rabbit & IgG & Santa Cruz Biotechnology & sc- 7870 & USA & $1: 50$ \\
\hline hCG $\beta$ & Polyclonal & Rabbit & $\mathrm{IgG}$ & Dako & A0231 & USA & $1: 50$ \\
\hline hPL & Polyclonal & Rabbit & IgG & Lab Vision & RB-9067-P & UK & $1: 50$ \\
\hline PLAP & $8 \mathrm{~B} 6$ & Mouse & $\operatorname{IgG} 2 \mathrm{a}$ & Chemicon International & CBL207 & USA & $1: 50$ \\
\hline
\end{tabular}

Table II. Details of assay ID for real-time PCR.

\begin{tabular}{lc}
\hline Gene & Assay ID \\
\hline Cytokeratin 7 & Hs00818825_m1 \\
HLA-G & Hs00918802_m1 \\
CD9 & Hs00233521_m1 \\
HPL & Hs01862611_g1 \\
PLAP & Hs01654626_s1 \\
Vimentin & Hs00185584_m1 \\
Integrin $\alpha-1$ & Hs00235006_m1 \\
Integrin $\alpha-6$ & Hs00173952_m1 \\
Integrin $ß-1$ & Hs00559595_m1 \\
Integrin $ß-4$ & Hs00236216_m1 \\
\hline
\end{tabular}

analysis. Total proteins $(20 \mu \mathrm{g})$ per sample was electrophoresed on a $4-20 \%$ SDS-polyacrylamide gel and transferred to a PDVF membrane. After washing in TBST $(0.1 \%$ Tween in Tris-buffered saline), the membrane was incubated with primary antibodies (anti-cytokeratin 7, 1:500; anti-E-cadherin, 1:500; anti-vimentin, 1:1000) for $1 \mathrm{~h}$ at $37^{\circ} \mathrm{C}$, before being washed in TBST and incubated with secondary HRPconjugated goat anti mouse or rabbit IgG goat antibodies (Santa Cruz Biotechnology, Santa Cruz, CA, USA) for $1 \mathrm{~h}$ at $37^{\circ} \mathrm{C}$. The antigen-antibody complexes were visualized using DAB.

Gelatin zymography. The gelatinolytic activities of matrix metalloproteinase-2 (MMP-2) and MMP-9 were assayed using gelatin zymography. Subconfluent cells were rinsed and cultured with serum-free medium for three days. The harvested medium was mixed 1:1 with $2 \mathrm{X}$ sample buffer [125 mM Tris- $\mathrm{HCl}(\mathrm{pH} 6.8), 4 \%$ SDS, 20\% glycerol] and was then applied to gels for electrophoresis without boiling under nonreducing conditions in a $10 \%$ acrylamide gel containing $1 \mathrm{mg} / \mathrm{ml}$ gelatin (Invitrogen Corp). After electrophoresis, the gels were washed at room temperature for $1 \mathrm{~h}$ in a buffer consisting of $50 \mathrm{mM}$ Tris- $\mathrm{HCl}(\mathrm{pH} 7.5)$ and
$2.5 \%$ Triton X-100 to remove SDS and were then incubated overnight in a buffer consisting of $50 \mathrm{mM}$ Tris- $\mathrm{HCl}(\mathrm{pH} 7.6)$, $150 \mathrm{mM} \mathrm{NaCl}, 10 \mathrm{mM} \mathrm{CaCl}$ and $0.05 \% \mathrm{NaN}_{3}$ at $37^{\circ} \mathrm{C}$. The gels were stained with $0.25 \%$ Coomassie Brilliant Blue R-250 in $50 \%$ methanol and $5 \%$ acetic acid for $60 \mathrm{~min}$ and destained in 5\% methanol and 7\% acetic acid. MMP-2 and MMP-9 were visualized as clear bands against a dark background at 72 and $92 \mathrm{kDa}$, respectively.

In vitro invasion assay. Invasion assays were carried out using BD Matrigel Invasion Chambers, 24-well plate, 8-mm pore size (BD Biosciences). Cells were seeded at a density of 25,000 cells/well in $500 \mu 1$ culture medium. Following incubation periods of 24 and $48 \mathrm{~h}$, the filter inserts were removed and washed twice with PBS and the upper side of the filter was cleaned with a cotton tipped swab. For assessment of the number of invaded cells, the filters were fixed and stained with $0.2 \%$ crystal violet in $4 \%$ formaldehyde. The total number of cells that had invaded onto the underside of the filter was counted manually under a light microscope.

Hypoxia-reoxygenation treatment. $\mathrm{HChEpC} 1 \mathrm{~b}$ cells were incubated under normoxic conditions $\left(20 \% \mathrm{O}_{2}\right)$ and then were subjected to hypoxia $\left(1 \% \mathrm{O}_{2}\right)$ for $1 \mathrm{~h}$ and subsequent reoxygenation under normoxic conditions $\left(20 \% \mathrm{O}_{2}\right)$ for $6 \mathrm{~h}$. At the end of each culture period, cells were scraped from culture dishes and were centrifuged and snap-frozen. All samples were stored at $-80^{\circ} \mathrm{C}$ before analysis and total RNA were isolated using the RNeasy mini kit (Qiagen).

Microarray analysis. Human genome-wide gene expression was examined using the Human Genome U133 Plus 2.0 Array (HG-U133 Plus 2.0 Set: GeneChip, Affymetrix, Santa Clara, CA, USA), which contains almost 45,000 probe sets, representing $>39,000$ transcripts derived from $\sim 33,000$ wellsubstantiated human genes (http://www.affymetrix.com/ products/arrays/specific/hgu133.affx). Double-stranded cDNA was synthesized and the cDNA was subjected to in vitro transcription in the presence of biotinylated nucleotide triphosphates. Ten micrograms of the biotinylated cRNA was hybridized with a probe array for $16 \mathrm{~h}$ at $45^{\circ} \mathrm{C}$ and the 
Table III. Expression of marker molecules for trophoblasts by immunocytochemistry.

\begin{tabular}{lcccc}
\hline & HChEpC1b & JAR & JEG-3 & Hs795Pl \\
\hline Cytokeratin 7a $^{2}$ & + & + & + & - \\
HLA-G & + & - & + & - \\
CD9 & + & + & + & + \\
Vimentin $^{\mathrm{a}}$ & + & - & - & + \\
E-cadherin $^{\mathrm{a}}$ & - & + & + & - \\
hCG $^{\text {hPL }}$ & + & + & + & - \\
PLAP & + & + & + & - \\
\hline
\end{tabular}

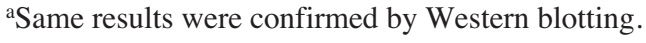

hybridized biotinylated cRNA was stained with streptavidinphycoerythrin and was then scanned with a Gene Array Scanner. The fluorescence intensity of each probe was quantified using the GeneChip Analysis Suite 5.0 software (Affymetrix). The expression level of a single RNA strand was set as the average fluorescence intensity among the intensities obtained from 11-paired (perfect-matched and single nucleotide-mismatched) probes consisting of 25-mer oligonucleotides. If the intensities of mismatched probes were very high, gene expression was judged to be absent even if a high average fluorescence was obtained with the Microarray Analysis Suite 5.0 program (MAS5.0). The data was processed with Affimetrix's default parameters, except for scaling (Target Intensity 1000), without normalization procedures to calculate the level of gene expression as the signal.

Statistics. Assuming the changes are reversible, the detection p-value at normoxic conditions (P1) should equal to that at subsequent reoxygenation (P3). Therefore, we deleted genes for which the value $\mathrm{P} 3 / \mathrm{P} 1$ was outside of the range 0.75-1.25. Then, we selected genes of which P2 x 2/ (P1 + P3) was $>2$, suggesting up-regulation by hypoxia ( $\mathrm{P} 2$ was the detection p-value under hypoxic conditions). On the other hand, genes for which $\mathrm{P} 2 \times 2 /(\mathrm{P} 1+\mathrm{P} 3)$ was $<0.5$, were defined as down-regulated. The analysis was performed with Excel (Microsoft Office Excel 2007).

\section{Results}

Immortalization of HChEpC cells. After transduction of hTERT and HPV16 E6/E7, the clone HChEpC1b demonstrated continuous growth for $>80$ passages, which is equivalent to 160 population doublings at a split ratio of 1:4. The population doubling time was $\sim 24 \mathrm{~h}$. As no indication of cellular crisis throughout this period was observed, the cells were considered to be virtually immortalized.

Extravillous trophoblast phenotype of HChEpClb. Immunocytochemistry was performed in JAR and JEG-3 cells, which are choriocarcinoma cell lines, and $\mathrm{Hs} 795 \mathrm{Pl}$, which is the

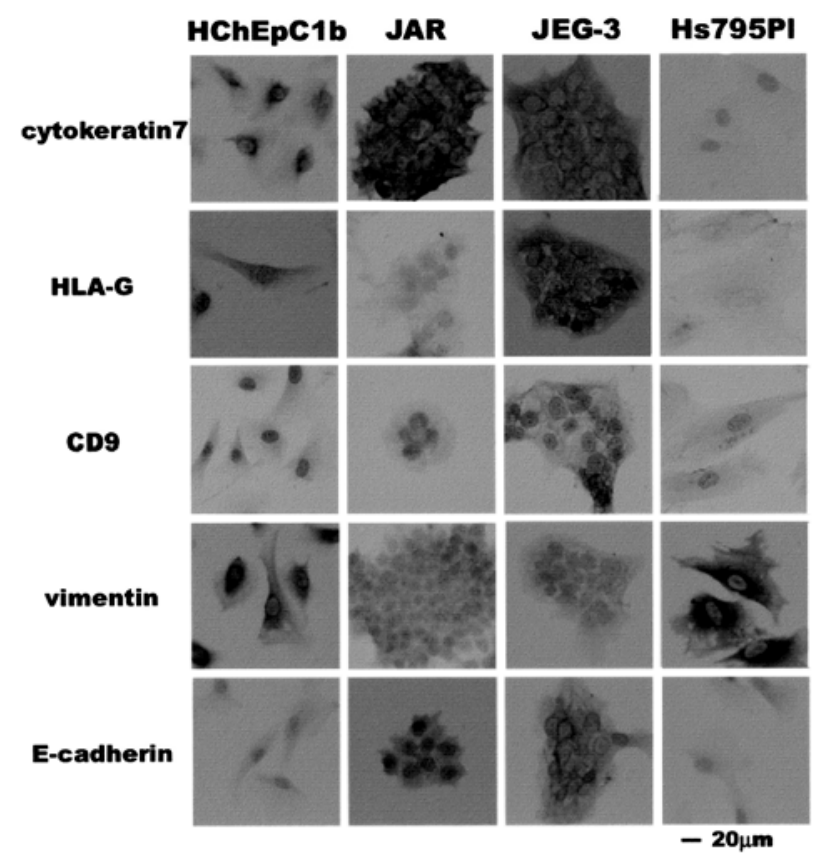

Figure 1. Immunocytochemistry of HChEpC1b, JAR, JEG-3 and Hs795Pl (each column, left to right), stained by cytokeratin 7, HLA-G, CD9, vimentin and E-cadherin (each row, top to bottom) at passage 75 .

fibroblast cell line that was derived from the term placenta. HChEpC1b showed positive staining for cytokeratin 7 , HLA-G, CD9, hCG, hPL, and vimentin, but was negative for E-cadherin and PLAP (Fig. 1 and Table III). As discussed in the international workshop on trophoblast cell lines (23), the minimum characteristic requirements for an extravillous trophoblast cell line are the positive expression of cytokeratin 7 , HLA-G and CD9. By immunocytochemistry, HChEpC1b showed expression of all of these extravillous markers. Some of these results were confirmed by Western blotting using the same antibodies.

Real-time RT-PCR demonstrated the same expression profiles as the immunological studies for CK7, HLA-G, CD7 and vimentin (Fig. 2.). The ability of these cells to produce hPL and PLAP was low compared to that of the choriocarcinoma cells. The integrin expression profile revealed an extravillous trophoblastic phenotype.

The transwell invasion assay showed the invasiveness of HChEpC1b (Fig. 3A) and gelatin zymography detected the secretion of MMP-2 and MMP-9 (Fig. 3B). These results fulfill the biological criteria of extravillous trophoblasts suggested in the IFPA Workshop (24).

Growth potential, karyotyping and transformed properties. G-banding staining of $\mathrm{HChEpC1b}$ was conducted at passage 6, 14, 25 and 75. Karyotype analysis exhibited almost normal chromosomal numbers ranging from 46 to 48 , but also contained minor structural alternations, probably associated with p53 inactivation (Table IV).

No tumors developed in nude mice after injection with HChEpC1b after a 3-month period. Therefore, immortalization of HChEpC1b was not accompanied by tumorigenic transformation. 
Table IV. Doubling time and karyotype of HChEpC1b.

\begin{tabular}{|c|c|c|c|}
\hline Passage & Doubling time $(\mathrm{h})$ & Chromosome no. & Karyotype \\
\hline 6 & 21.3 & 47 & $\begin{array}{l}47, \mathrm{XY},+20[18] / \\
47, \mathrm{idem},-14,+\operatorname{mar}[2]\end{array}$ \\
\hline 14 & ND & $46-47$ & $\begin{array}{l}47, \mathrm{XY},+20[2] / \\
47, \mathrm{idem},-14,+\operatorname{mar}[12] / \\
46, \mathrm{XY}[6]\end{array}$ \\
\hline 25 & 24 & $46-48$ & $\begin{array}{l}\text { 47,XY,+20[7]/ } \\
\text { 47,idem,-14,+mar[6]/ } \\
\text { 46,idem,der(4;16)(p10;q10)[1]/ } \\
\text { 48,idem,+6[1]/ } \\
\text { 47,idem,i(14)(q10)[1]/47,XY,+14[1]/ } \\
\text { 46,XY[3] }\end{array}$ \\
\hline 75 & 23.9 & $46-47$ & $\begin{array}{l}\text { 46,XY,add(11)(q13or21),-13,+20[14]/ } \\
\text { 46,idem,+14,der(14;21)(q10;q10)[1]/ } \\
\text { 47,idem,+der(1;2)(p10;q10),add(14)(p10),add(14)(q22)[1]/ } \\
\text { 46,idem,t(13;16)(p10;p10)[1]/ } \\
\text { 46,idem, } \text { add(18)(q12)[1]/ } \\
\text { 47,idem,+mar1[1]/ } \\
\text { 46,idem,-18,+mar2[1] }\end{array}$ \\
\hline
\end{tabular}
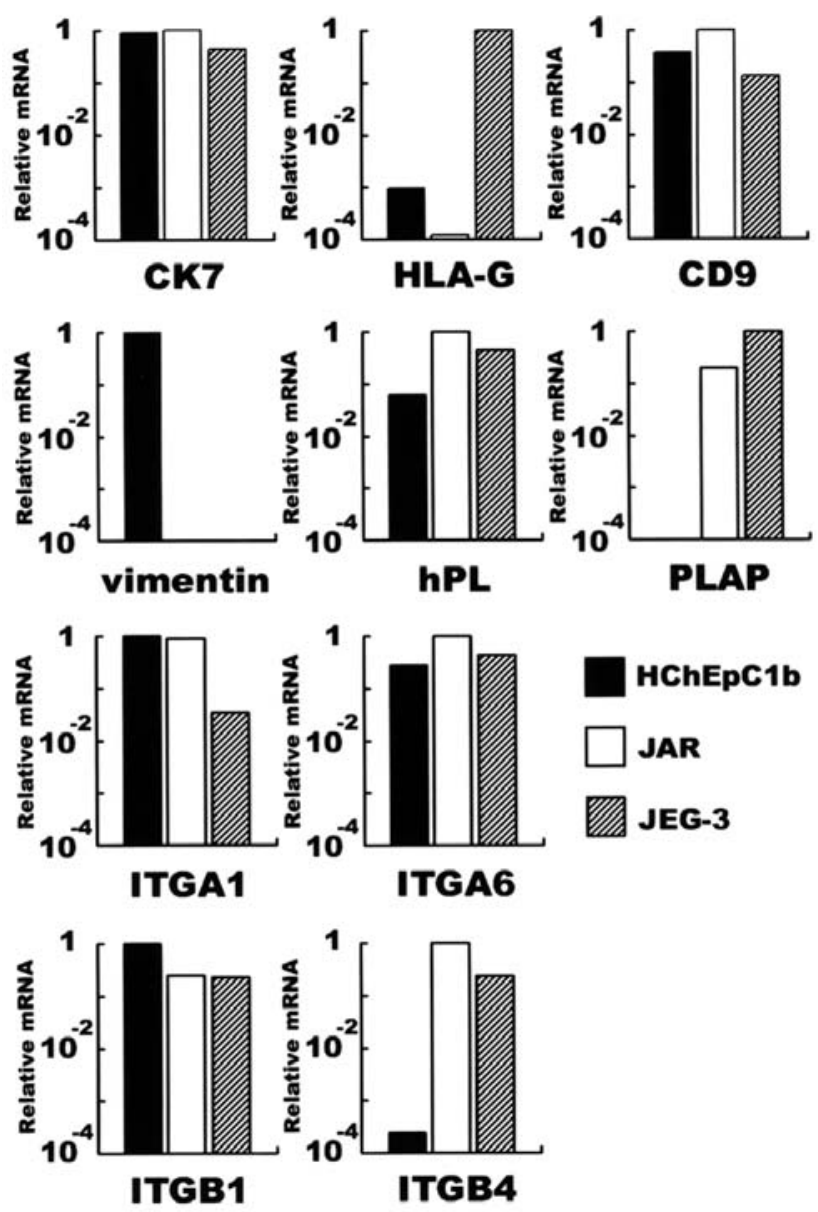

Figure 2. Real-time RT-PCR to detect the mRNA expression of molecular markers for trophoblast characterization.

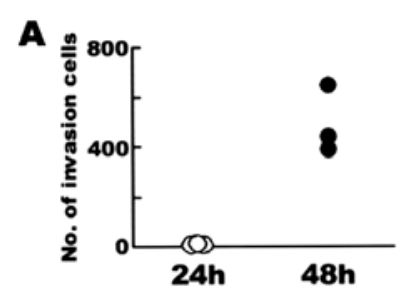

B

Figure 3. (A) A transwell insert invasion assay to show the invasiveness of HChEpC1b. The number of cells indicates the total count of cells that invaded through the insert membrane, which is coated with Matrigel Matrix, toward the underside of the membrane. (B) Gelatin zymography showing the secretion of MMP-9 and MMP-2.

Responsiveness to hypoxia reoxygenation treatment. The up-regulated and down-regulated genes that showed reversible expression in hypo-normo oxidative conditions are shown in Tables V and VI, respectively.

\section{Discussion}

In the present study, we established the cell line $\mathrm{HChEpC1b}$, that acquired immortality after HPV16 E6/E7 and hTERT introduction. This cell line expressed molecular markers for human extravillous trophoblasts, including cytokeratin 7, HLA-G and CD9. Study of the biology of trophoblasts has been limited by the lack of suitable cell models that represent this unique cell population in vitro. In the past, choriocarcinoma cell lines, such as BeWo (25), JEG (26) and JAR (27) were the only immortal cell lines available and have been used extensively to study placental functions regardless of limitations related to their malignant origins. Recently, several cell lines have been established by transfection with viral 
Table V. Up-regulated genes showing reversible expression in hypo-normo oxidative conditions.

\begin{tabular}{|c|c|}
\hline UniGene ID_Affymetrix & Gene title \\
\hline Hs.427236 & MyoD family inhibitor domain containing \\
\hline Hs.431081 & Ubiquitin-specific peptidase 53 \\
\hline Hs.29725 & Hypothetical protein FLJ13197 \\
\hline Hs.435991 & Chromosome 4 open reading frame 16 \\
\hline Hs.469970 & Splicing factor, arginine/serine-rich 4 \\
\hline Hs.522074 & TSC22 domain family, member 3 \\
\hline Hs.631772 & Solute carrier family 25 (mitochondrial carrier; ornithine transporter) member 15 \\
\hline--- & Zinc finger protein 252 \\
\hline Hs.533499 & Membrane-associated DNA binding protein \\
\hline Hs.492348 & SLAM family member 6 \\
\hline Hs. 469840 & Cytoplasmic linker-associated protein 1 \\
\hline Hs.369430 & Peptidylglycine $\alpha$-amidating monooxygenase \\
\hline Hs. 436121 & Coiled-coil domain containing 112 \\
\hline Hs.459790 & Vacuolar protein sorting 13 homolog A (S. cerevisiae) \\
\hline Hs.302085 & Prostaglandin I2 (prostacyclin) synthase /// prostaglandin I2 (prostacyclin) synthase \\
\hline Hs. 157818 & Potassium voltage-gated channel, shaker-related subfamily, $ß$ member 1 \\
\hline Hs.413801 & Proteasome (prosome, macropain) activator subunit 4 \\
\hline Hs.512152 & HLA-G histocompatibility antigen, class I, G \\
\hline Hs. 124565 & Solute carrier family 23 (nucleobase transporters), member 3 \\
\hline Hs.441124 & Apolipoprotein B mRNA editing enzyme, catalytic polypeptide-like 3F \\
\hline
\end{tabular}

Table VI. Down-regulated genes showing reversible expression in hypo-normo oxidative conditions.

\begin{tabular}{|c|c|}
\hline UniGene ID_Affymetrix & Gene title \\
\hline Hs.368912 & Dipeptidyl-peptidase 4 (CD26, adenosine deaminase complexing protein 2) \\
\hline Hs. 357128 & Molybdenum cofactor synthesis 1 /// molybdenum cofactor synthesis 1 \\
\hline Hs.533499 & Membrane associated DNA binding protein \\
\hline Hs.617709 & Chromosome 1 open reading frame 136 \\
\hline Hs.12929 & Chromosome 17 open reading frame 80 \\
\hline Hs.470907 & Adenylate kinase 2 \\
\hline Hs.471040 & Hypothetical protein FLJ38973 \\
\hline Hs.529577 & U2-associated SR140 protein \\
\hline Hs.478000 & Muscleblind-like (Drosophila) \\
\hline Hs.502182 & Brain-derived neurotrophic factor \\
\hline Hs.443301 & Centrosomal protein $63 \mathrm{kDa}$ \\
\hline Hs.321176 & $\begin{array}{l}\text { Transcribed locus, weakly similar to XP_850647.1 PREDICTED: similar to } \\
\text { LINE-1 reverse transcriptase homolog [Canis familiaris] }\end{array}$ \\
\hline Hs.28780 & Zinc finger protein 449 \\
\hline Hs.554740 & Fanconi anemia, complementation group B \\
\hline Hs.340623 & Hypothetical protein LOC644873 \\
\hline Hs.569809 & Rho GTPase activating protein 27 \\
\hline Hs.461860 & Nucleoporin $214 \mathrm{kDa}$ \\
\hline Hs.452398 & MRNA; cDNA DKFZp564E143 (from clone DKFZp564E143) \\
\hline Hs.16004 & Chromosome 10 open reading frame 76 \\
\hline Hs.612891 & Hypothetical protein FLJ21272 \\
\hline Hs.59159 & Chromodomain helicase DNA binding protein 9 \\
\hline Hs.397001 & CDNA clone IMAGE:4304686 \\
\hline Hs.512682 & Carcinoembryonic antigen-related cell adhesion molecule 1 (biliary glycopr \\
\hline
\end{tabular}


oncogenes. The most commonly used gene was the early region of SV40 containing the small and large T-antigens that bind to and inactivate $\mathrm{p} 53$ and $\mathrm{Rb}$. Although the expression of the T-antigen extends the life span of the cells, the onset of cellular senescence is inevitable. This is associated with a reduction of telomere length. Other commonly used viral genes include HPV16 E6 and E7, which inhibit the functions of p53 and $\mathrm{Rb}$ respectively. E6 has been reported to activate telomerase (28), which can stabilize the chromosome profile and avoid an immortalization-related crisis. Therefore, we infected human trophoblast cells with retroviral expression vectors containing type 16 human papillomaviruses E6 and E7 in combination with hTERT to obtain immortalized trophoblast cells showing approxinately diploid chromosomes.

Although cytokeratin-positive, vimentin-negative phenotypes are regarded as markers of trophoblast lineage (24), HChEpC1b expressed both cytokeratin and vimentin. Coexpression of cytokeratin and vimentin by extravillous trophoblasts was reported earlier (29), which is a characteristic similar to that of some cancer cells of epithelial origin (30-32), as part of an epithelial-mesenchymal transition $(33,34)$. On the other hand, E6 is known to up-regulate vimentin (35) and another trophoblast cell line immortalized by E6/E7, TEV-1, was reported to express vimentin. From our results, it is difficult to distinguish whether the origin of HChEpC1b was the vimentin-positive extravillous trophoblasts or the vimentin negative trophoblasts that displayed the mesenchymal phenotype after E6 introduction. To answer this problem, further study is needed to compare the effects of E6 on each trophoblast population.

We obtained 43 genes that showed reversible up- or down-regulation during hypoxia. There are several interesting up-regulated genes including that for the MyoD family inhibitor domain containing protein isoform $\mathrm{p} 40$, which is involved in repair of muscle injury in ischemic microenvironments (36); prostaglandin I2 synthase, which is a potent vasodilator and inhibitor of platelet aggregation and plays an important role in the predisposition to lung cancer (37); human leukocyte antigen G (HLA-G) molecule, which plays an important role in immune response regulation and has been implicated in the inhibition of the cytolytic function of natural killer and cytotoxic T cells (38); and apolipoprotein B mRNA editing enzyme, a catalytic polypeptide-like 3C, which plays roles in growth or cell cycle control (39). Among the interesting down-regulated genes, there were adenylate kinase 2, which is localized in the mitochondrial intermembrane space and may play a role in apoptosis (40); BDNF brain-derived neurotrophic factor, which plays a role in the regulation of stress response and in the biology of mood disorders (41); and carcinoembryonic antigen-related cell adhesion molecule 1 , which plays roles in the differentiation and arrangement of tissue three-dimensional structure, angiogenesis, apoptosis, tumor suppression, metastasis and the modulation of innate and adaptive immune responses (42). In future, we should confirm the expression of these genes by real-time RT-PCR and further examination should focus on a functional assay of these candidate genes to assess whether they play important roles during hypoxia.

In summary, we established a newly immortalized trophoblast cell line via infection with HPV16 E6/E7 in combination with hTERT and this cell line is a useful model for the study of extravillous trophoblast function.

\section{Acknowledgements}

This study was supported in part by Grants-in-Aid from the Ministry of Health, Labor and Welfare of Japan.

\section{References}

1. Benirschke K, Kaufmann P and Baergen RN: Pathology of the Human Placenta. 5th edition, Springer, New York, 2005.

2. Redman CW and Sargent IL: Latest advances in understanding preeclampsia. Science 308: 1592-1594, 2005.

3. Allsopp RC, Vaziri H, Patterson C, et al: Telomere length predicts replicative capacity of human fibroblasts. Proc Natl Acad Sci USA 89: 10114-10118, 1992.

4. Saretzki G, Sitte N, Merkel U, Wurm RE and von Zglinicki T: Telomere shortening triggers a p53-dependent cell cycle arrest via accumulation of G-rich single stranded DNA fragments. Oncogene 18: 5148-5158, 1999

5. Kiyono T, Foster SA, Koop JI, McDougall JK, Galloway DA and Klingelhutz AJ: Both Rb/p16INK4a inactivation and telomerase activity are required to immortalize human epithelial cells. Nature 396: 84-88, 1998.

6. Rheinwald JG, Hahn WC, Ramsey MR, et al: A two-stage, p16(INK4A)- and p53-dependent keratinocyte senescence mechanism that limits replicative potential independent of telomere status. Mol Cell Biol 22: 5157-5172, 2002.

7. Graham CH, Hawley TS, Hawley RG, et al: Establishment and characterization of first trimester human trophoblast cells with extended lifespan. Exp Cell Res 206: 204-211, 1993.

8. Ho CK, Chiang H, Li SY, Yuan CC and Ng HT: Establishment and characterization of a tumorigenic trophoblast-like cell line from a human placenta. Cancer Res 47: 3220-3224, 1987.

9. Ho CK, Li SY, Yu KJ, Wang CC, Chiang H and Wang SY: Characterization of a human tumorigenic, poorly differentiated trophoblast cell line. In Vitro Cell Dev Biol Anim 30A: 415-417, 1994.

10. Morgan M, Kniss D and McDonnell S: Expression of metalloproteinases and their inhibitors in human trophoblast continuous cell lines. Exp Cell Res 242: 18-26, 1998.

11. Rong-Hao L, Luo S and Zhuang LZ: Establishment and characterization of a cytotrophoblast cell line from normal placenta of human origin. Hum Reprod 11: 1328-1333, 1996.

12. Zdravkovic M, Aboagye-Mathiesen G, Guimond MJ, Hager H, Ebbesen P and Lala PK: Susceptibility of MHC class I expressing extravillous trophoblast cell lines to killing by natural killer cells. Placenta 20: 431-440, 1999.

13. Chou JY: Establishment of clonal human placental cells synthesizing human choriogonadotropin. Proc Natl Acad Sci USA 75: 1854-1858, 1978.

14. Choy MYand Manyonda IT: The phagocytic activity of human first trimester extravillous trophoblast. Hum Reprod 13: 2941-2949, 1998.

15. Khoo NK, Bechberger JF, Shepherd T, et al: SV40 Tag transformation of the normal invasive trophoblast results in a premalignant phenotype. I. Mechanisms responsible for hyperinvasiveness and resistance to anti-invasive action of TGFbeta. Int J Cancer 77: 429-439, 1998.

16. Lei KJ, Gluzman Y, Pan CJ and Chou JY: Immortalization of virus-free human placental cells that express tissue-specific functions. Mol Endocrinol 6: 703-712, 1992.

17. Lewis MP, Clements M, Takeda S, et al: Partial characterization of an immortalized human trophoblast cell-line, TCL-1, which possesses a CSF-1 autocrine loop. Placenta 17: 137-146, 1996.

18. Feng HC, Choy MY, Deng W, et al: Establishment and characterization of a human first-trimester extravillous trophoblast cell line (TEV-1). J Soc Gynecol Investig 12: e21-e32, 2005.

19. Shih I, Wang T, Wu T, Kurman RJ and Gearhart JD: Expression of Mel-CAM in implantation site intermediate trophoblastic cell line, IST-1, limits its migration on uterine smooth muscle cells. J Cell Sci 111 ( Pt 17): 2655-2664, 1998.

20. Wang YL, Qiu W, Feng HC, et al: Immortalization of normal human cytotrophoblast cells by reconstitution of telomeric reverse transcriptase activity. Mol Hum Reprod 12: 451-460, 2006. 
21. Kyo S, Nakamura M, Kiyono K, et al: Successful immortalization of endometrial glandular cells with normal structural and functional characteristics. Am J Pathol 163: 2259-2269, 2003.

22. Naviaux RK, Costanzi E, Haas M and Verma IM: The pCL vector system: rapid production of helper-free, high-titer, recombinant retroviruses. J Virol 70: 5701-5705, 1996.

23. Shiverick KT, King A, Frank H, Whitley GS, Cartwright JE and Schneider H: Cell culture models of human trophoblast II: trophoblast cell lines - a workshop report. Placenta 22 (Suppl A): S104-S106, 2001.

24. Morrish DW, Whitley GS, Cartwright JE, Graham CH and Caniggia I: In vitro models to study trophoblast function and dysfunction - a workshop report. Placenta 23 (Suppl A): S114S118, 2002.

25. Pattillo RA and Gey GO: The establishment of a cell line of human hormone-synthesizing trophoblastic cells in vitro. Cancer Res 28: 1231-1236, 1968

26. Kohler PO and Bridson WE: Isolation of hormone-producing clonal lines of human choriocarcinoma. J Clin Endocrinol Metab 32: 683-687, 1971.

27. Hussa RO, Story MT and Pattillo RA: Regulation of human chorionic gonadotropin (hCG) secretion by serum and dibutyryl cyclic AMP in malignant trophoblast cells in vitro. J Clin Endocrinol Metab 40: 401-405, 1975.

28. Gewin L, Myers H, Kiyono T and Galloway DA: Identification of a novel telomerase repressor that interacts with the human papillomavirus type-16 E6/E6-AP complex. Genes Dev 18: 2269-2282, 2004.

29. Aboagye-Mathiesen G, Laugesen J, Zdravkovic M and Ebbesen P: Isolation and characterization of human placental trophoblast subpopulations from first-trimester chorionic villi. Clin Diagn Lab Immunol 3: 14-22, 1996.

30. Azumi $\mathrm{N}$ and Battifora $\mathrm{H}$ : The distribution of vimentin and keratin in epithelial and nonepithelial neoplasms. A comprehensive immunohistochemical study on formalin - and alcohol-fixed tumors. Am J Clin Pathol 88: 286-296, 1987.

31. McNutt MA, Bolen JW, Gown AM, Hammar SP and Vogel AM: Coexpression of intermediate filaments in human epithelial neoplasms. Ultrastruct Pathol 9: 31-43, 1985.
32. Ramaekers FC, Haag D, Kant A, Moesker O, Jap PH and Vooijs GP: Coexpression of keratin - and vimentin-type intermediate filaments in human metastatic carcinoma cells. Proc Natl Acad Sci USA 80: 2618-2622, 1983.

33. Christiansen JJ and Rajasekaran AK: Reassessing epithelial to mesenchymal transition as a prerequisite for carcinoma invasion and metastasis. Cancer Res 66: 8319-8326, 2006.

34. Ferretti C, Bruni L, Dangles-Marie V, Pecking AP and Bellet D: Molecular circuits shared by placental and cancer cells, and their implications in the proliferative, invasive and migratory capacities of trophoblasts. Hum Reprod Update 13: 121-141, 2007.

35. Duffy CL, Phillips SL and Klingelhutz AJ: Microarray analysis identifies differentiation-associated genes regulated by human papillomavirus type 16 E6. Virology 314: 196-205, 2003.

36. Yun Z, Lin Q and Giaccia AJ: Adaptive myogenesis under hypoxia. Mol Cell Biol 25: 3040-3055, 2005.

37. Stearman RS, Grady MC, Nana-Sinkam P, Varella-Garcia M and Geraci MW: Genetic and epigenetic regulation of the human prostacyclin synthase promoter in lung cancer cell lines. Mol Cancer Res 5: 295-308, 2007.

38. Castelli EC, Mendes-Junior CT, Viana de Camargo JL and Donadi EA: HLA-G polymorphism and transitional cell carcinoma of the bladder in a Brazilian population. Tissue Antigens 72: 149-157, 2008

39. Kock J and Blum HE: Hypermutation of hepatitis B virus genomes by APOBEC3G, APOBEC3C and APOBEC3H. J Gen Virol 89: 1184-1191, 2008.

40. Lee HJ, Pyo JO, Oh Y, et al: AK2 activates a novel apoptotic pathway through formation of a complex with FADD and caspase-10. Nat Cell Biol 9: 1303-1310, 2007.

41. Licinio J and Wong ML: Brain-derived neurotrophic factor (BDNF) in stress and affective disorders. Mol Psychiatry 7: 519, 2002.

42. Gray-Owen SD and Blumberg RS: CEACAM1: contactdependent control of immunity. Nat Rev Immunol 6: 433-446, 2006. 